\title{
Europe des Douze et démographie
}

A la veille, ou l'avant-veille, de l'instauration du «grand marché intérieur européen », l'Institut national d'études démographiques (INED) rappelle quelques données démographiques intéressantes [1]. La figure 1 représente la pyramide des âges en Europe, établie pour la première fois en 1987 par un chercheur de l'INED, comparée à celle de la France en données proportionnelles [2]. On y reconnaît l'incisure classique due à la Première Guerre Mondiale, mais curieusement pas de régression nette en 1940-1945; l'incisure propre à la France est surtout due à une forte baisse de la natalité au cours des années 30. Après la forte poussée nataliste de 1945, l'événement le plus marquant est la chute depuis 1964 : le nombre de naissances annuelles est passé, dans l'Europe des Douze, de 5,6 millions en 1964 à 3,8 millions en 1986. La France est relativement épargnée, passant d'environ 830000 à 760000 ; la baisse en France a eu lieu, comme on le voit sur la figure 1 , dans les années qui ont précédé la légalisation de l'avortement et non après.

Le Tableau I résume les données sur la population de l'Europe. On peut constater qu'elle est supérieure à celles des USA et de l'URSS, mais non de l'ensemble URSS + Europe de l'Est. Bien que son taux de fécondité soit inférieur à l'indice nécessaire pour le renouvellement des générations (2,10 enfants par femme), la France est un des seuls pays qui garde un certain accroissement (environ 200000 par an). La RFA et le Danemark sont déjà en baisse, et l'Italie, qui a battu récemment tous les records de faible natalité (moins de 10 p. 1000) ne tardera pas à les rejoindre. L'accroissement de la population européenne est plus faible que celui des USA, de l'URSS, sans parler, bien entendu, du Tiers-
Monde.

Le Tableau II montre la répartition des étrangers dans les pays de la CEE, et, parmi eux, de ceux qui ne font pas partie de l'Europe des Douze. C'est en RFA, puis en France, que leur nombre et leur proportion sont les plus élevés. L'article [1] insiste sur la façon différente qu'ont les divers pays d'accorder, ou de refuser, l'octroi de leur citoyenneté aux étrangers fixés sur leur sol, mais aussi sur la méconnaissance du sort des Européens résidant hors d'Europe. Il plaide enfin, non pour que les dif-

férences soient abolies, mais pour une meilleure connaissance réciproque des politiques familiales et du comportement vis-à-vis des étrangers, permettant à terme des tentatives d'harmonisation.

J.-C. D

1. Lévy ML. Europe et Démographie. Population et Sociétés, INED n²30, décembre 1988.

2. Chesnais JC. Population trends in the European Community 1960-1986, Rev Eur Population 1987 ; 3 : 281-96.

3. Statistiques démographiques. Office Staistique des Communautés européennes. Eurostat, Série Jaune, 1988.

\begin{tabular}{|c|c|c|c|c|}
\hline \multicolumn{5}{|c|}{$\begin{array}{l}\text { Tableau I } \\
\text { ACCROISSEMENT NATUREL } \\
\text { COMMUNAUTAIRE (1986) }\end{array}$} \\
\hline \multirow{2}{*}{\multicolumn{2}{|c|}{$\begin{array}{l}\text { Population (a) } \\
\text { (milliers) }\end{array}$}} & \multicolumn{3}{|c|}{ Taux } \\
\hline & & $\begin{array}{c}\text { Natalité (a) } \\
\text { (p. } 1000 \text { hab.) }\end{array}$ & $\begin{array}{l}\text { Mortalité (b) } \\
\text { (p. } 1000 \text { hab.) }\end{array}$ & $\begin{array}{c}\text { Accroissement } \\
\text { naturel } \\
\text { (\% par an) }\end{array}$ \\
\hline $\begin{array}{l}\text { RFA } \\
\text { Belgique } \\
\text { Danemark } \\
\text { Espagne } \\
\text { France } \\
\text { Grèce } \\
\text { Irlande } \\
\text { Italie } \\
\text { Luxembourg } \\
\text { Pays-Bas } \\
\text { Portugal } \\
\text { Royaume-Uni } \\
\text { Europe des Douze }\end{array}$ & $\begin{array}{r}61066 \\
9862 \\
5121 \\
38668 \\
55394 \\
9966 \\
3541 \\
52246 \\
370 \\
14572 \\
10208 \\
56763 \\
322776\end{array}$ & $\begin{array}{r}10,3 \\
11,9 \\
10,8 \\
12,1 \\
14,1 \\
11,3 \\
17,3 \\
9,7 \\
11,7 \\
12,7 \\
12,4 \\
13,3 \\
11,9\end{array}$ & $\begin{array}{r}11,5 \\
11,2 \\
11,3 \\
7,7 \\
9,9 \\
9,2 \\
9,5 \\
9,5 \\
10,7 \\
8,6 \\
9,4 \\
11,7 \\
9,1\end{array}$ & $\begin{array}{r}-0,23 \\
0,07 \\
-0,05 \\
0,44 \\
0,42 \\
0,21 \\
0,78 \\
0,02 \\
0,10 \\
0,41 \\
0,30 \\
0,16 \\
0,28\end{array}$ \\
\hline $\begin{array}{l}\text { URSS } \\
\text { États-Unis } \\
\text { Japon }\end{array}$ & $\begin{array}{l}280140 \\
241600 \\
121490\end{array}$ & $\begin{array}{l}19,4 \\
15,5 \\
11,5\end{array}$ & $\begin{array}{r}10,6 \\
8,7 \\
6,2\end{array}$ & $\begin{array}{l}0,88 \\
0,68 \\
0,53\end{array}$ \\
\hline Monde & 4917000 & 26 & 10 & 1,6 \\
\hline
\end{tabular}

(a) Moyenne 1986, sauf: Irlande et Luxembourg (31 décembre), Grèce et Royaume-Uni (30 juin). (b) 1984 pour I'Espagne, 1985 pour I'URSS.

Source : Eurostat [3], p. 36 


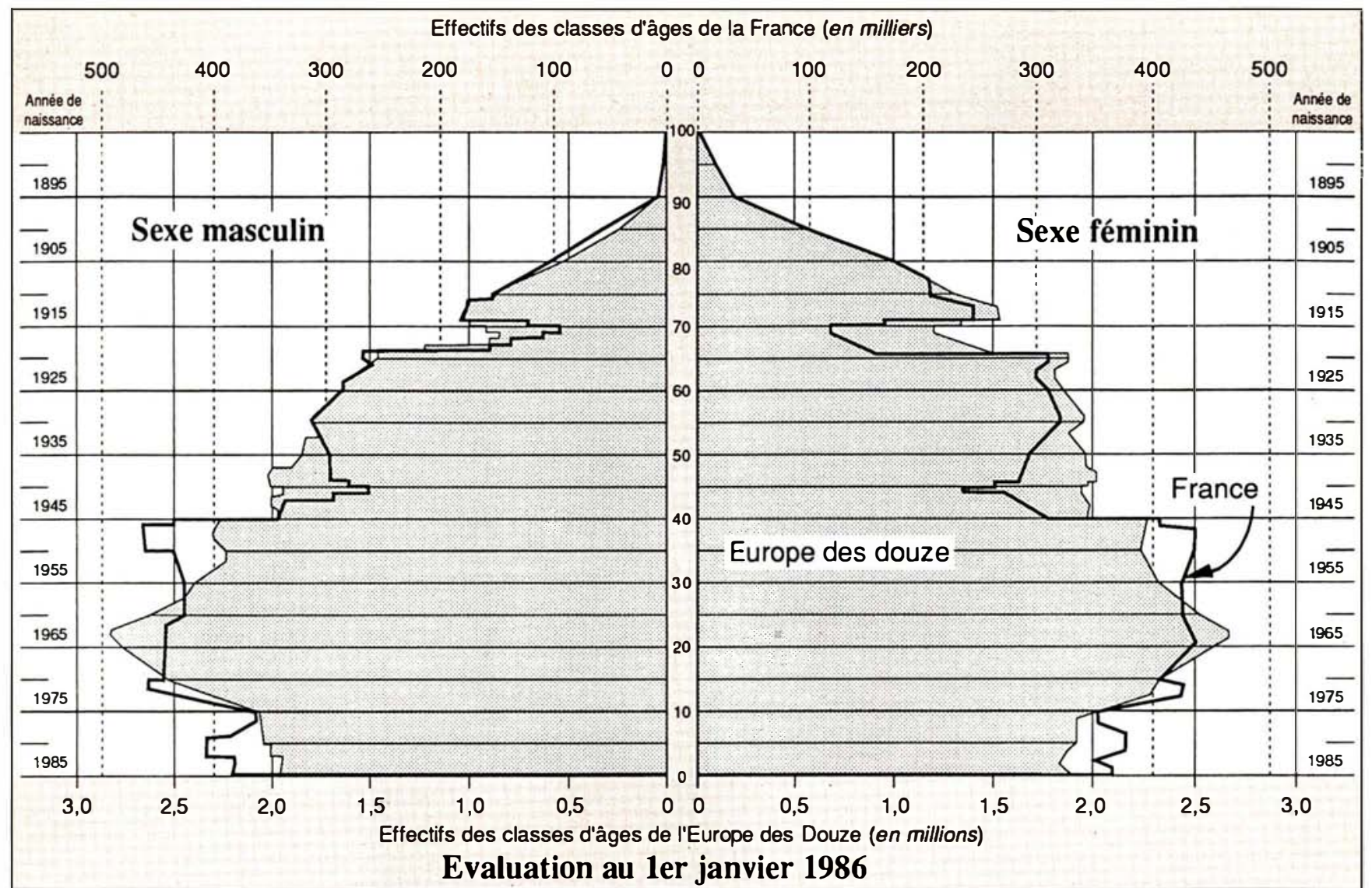

Figure 1. Pyramides des âges de l'Europe des Douze (322 millions d'habitants) et de la France (55 millions

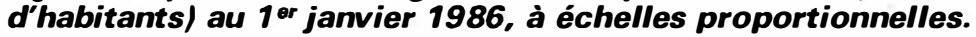

\begin{tabular}{|c|c|c|c|}
\hline \multicolumn{4}{|c|}{$\begin{array}{c}\text { Tableau II } \\
\text { ÉTRANGERS DANS L'EUROPE COMMUNAUTAIRE }\end{array}$} \\
\hline \multirow{2}{*}{$\begin{array}{l}\text { Population } \\
\text { (milliers) }\end{array}$} & \multicolumn{2}{|c|}{ Nationalités } & \multirow{2}{*}{$\begin{array}{c}\text { Hors } \\
\text { Communauté (a) } \\
(\%)\end{array}$} \\
\hline & Des Douze & Autres & \\
\hline $\begin{array}{l}\text { RFA } 1986 \\
\text { Belgique } 1985 \\
\text { Danemark } 1986 \\
\text { Espagne } 1984 \\
\text { France } 1982 \\
\text { Grèce } 1985 \\
\text { Irlande } \\
\text { Italie } \\
\text { Luxembourg } 1981 \\
\text { Pays-Bas } 1986 \\
\text { Portugal } 1986 \\
\text { Royaume-Uni } 1984 \\
\text { Ensemble (a) }\end{array}$ & $\begin{array}{r}1364,7 \\
583,9 \\
25,7 \\
134,2 \\
1577,9 \\
228,5\end{array}$ & $\begin{array}{r}3148,0 \\
313,7 \\
91,3 \\
93,3 \\
2102,2 \\
67,4\end{array}$ & $\begin{array}{l}5,1 \\
3,2 \\
1,8 \\
0,2 \\
3,8 \\
0,7\end{array}$ \\
\hline
\end{tabular}

(a) Proportion de nationalités hors Communauté dans la population totale. Chiffres indicatifs, les données étant relatives à des dates différentes. Source : Eurostat [13], tableau 12. 